Transport

Volume 169 Issue TR2

Chemical pavement modifications to reduce ice adhesion

Wright, Parry and Airey
Proceedings of the Institution of Civil Engineers

Transport 169 April 2016 Issue TR2

Pages 76-87 http://dx.doi.org/10.1680/jtran.14.00053

Paper 1400053

Received 20/08/2014

Published online 08/02/2016

Accepted 14/10/2015

Keywords: pavement design/safety \& hazards

\title{
Chemical pavement modifications to reduce ice adhesion
}

1 Michael Wright PhD, MEng(Hons), CEng, MICE, MCIHT Senior Pavement Engineer, Jean Lefebvre (UK), Cheshunt, UK

2 Tony Parry PhD, BSc, MCIHT

Associate Professor, Nottingham Transportation Engineering Centre, The University of Nottingham, Nottingham, UK
3 Gordon Airey PhD, MCIHT

Professor, Director, Nottingham Transportation Engineering Centre, The University of Nottingham, Nottingham, UK
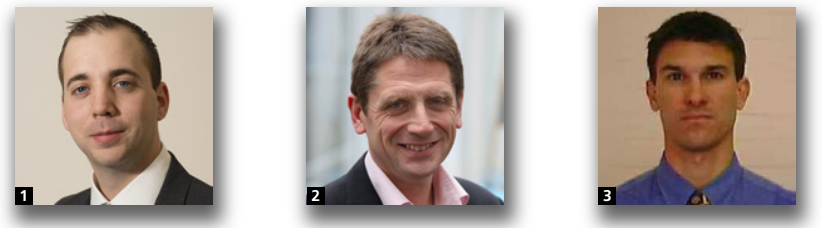

The formation of ice and snow on road pavement surfaces is a recurring problem, creating hazardous driving conditions, restricting public mobility as well as having adverse economic effects. It would be desirable to develop new and improved ways of modifying the pavement surface, to prevent or at least delay the build-up of ice and to weaken the pavement-ice bond, and making the ice which forms easier to remove. This development could lead to economic, environmental and safety benefits for winter service providers and road users. This paper describes how environmental scanning electron microscopy was used to examine the mechanism by which de-icing chemicals, added as a filler replacement to bituminous materials, can be transferred to the pavement surface. The paper assesses the potential for chemical modifications to reduce the adhesion between ice and the pavement surface by means of work of adhesion calculations, based on surface energy parameters and a new physical ice bond test. The paper also examines the influence that the chemical modifications have on the durability of the pavement surface course.

\section{Notation}

$\Delta G_{\mathrm{BA}}^{\mathrm{a}} \quad$ adhesive bond strength between two materials 'A' and ' $\mathrm{B}$ '

$\gamma \quad$ total surface free energy

$\gamma^{+} \quad$ Lewis acid component

$\gamma^{-} \quad$ Lewis base component

$\gamma^{\mathrm{AB}} \quad$ acid/base (polar) component

$\gamma^{\text {LW }} \quad$ Lifshitz Van der Waals component

\section{Introduction}

The formation of ice and snow on road pavement surfaces creates hazardous driving conditions, restricts public mobility and has adverse economic effects. Hazardous driving conditions are caused by a reduction in the coefficient of friction between vehicle tyres and the pavement surface (Kuemmel and Hanbali, 1992). Accident analysis and the associated economic impacts have been studied in detail by Goodwin (2002), Hanke and Levin (1988), Quarmby et al. (2010), Strong et al. (2010), Thornes (2000) and Usman et al. (2010).

Winter service is undertaken by highway authorities to ensure, as far as possible, that road users can travel safely and with minimum disruption in cold conditions. Such operations primarily consist of the application of de-icing chemicals pro-actively and reactively to the pavement surface. The de-icing chemicals form a solution to prevent ice formation by lowering the freezing point and/or weakening the bond between the ice and the pavement surface. The delivery of winter service and application of de-icing chemicals pro-actively and reactively are discussed by COST (2002), PIARC (2014) and Road Liaison Group (2014).

Several fundamental features of both the pavement, including the small-scale roughness and the high surface energy, and the ice lead to excellent bonding between the two, with the result that bond prevention is difficult (Penn and Meyerson, 1992). High bond strengths are also formed owing to the properties of water. The low viscosity of water allows good contact and relatively large energy of interaction with the pavement. Penn and Meyerson (1992) identified that 'the pavement nucleates small, bubble-free ice crystals that are strong and difficult to remove mechanically'.

The build-up of ice on pavement surfaces is a recurring problem requiring a correctly timed application of de-icing chemicals to prevent unsafe conditions developing for individual winter weather events. This has significant economic (labour, plant 
and materials) and environmental impacts (Avery, 1973; Backman and Folkeson, 1996; D'Itri, 1992; Schraufnagel, 1973). It would therefore be 'desirable to develop new and improved ways of modifying the highway surface, to prevent or at least delay the build-up of ice, and to weaken the pavementice bond so that the ice which forms is easier to remove' (Baum et al., 1992: pp. 3-4).

One area that has previously been considered in order to improve current practice is the modification of the pavement surface course. 'Both physical and chemical modifications of the pavement surface are candidates for preventing the formation of ice or for reducing the strength of adhesion to a level that permits fast, complete, and low-force removal of ice or compacted snow' (Baum et al., 1992: p. 1). Delaying the formation of ice and/or weakening the bond between the ice and the pavement could generate a number of benefits including

a reduction in the frequency of precautionary de-icing currently undertaken

- a reduction in the amount of sodium chloride or other deicing chemicals applied and the associated environmental impacts and economic costs

- improved road safety.

Initial investigations by Baum et al. (1992) indicated that the incorporation of chemical additives has the potential to provide anti-icing benefits. Despite this, research relating to the chemical transfer mechanism and performance of such modifications is severely limited. Research has generally been focused on improving the tried and tested methods of applying de-icing chemicals to the road surface, such as pre-wetting (Burtwell, 2004), spreading performance (Evans, 2012), impacts of changes in winter severity (PIARC, 2013) and extreme cold weather conditions (Evans et al., 2012).

The aim of this paper is to examine the transfer of de-icing chemicals from within a bituminous mastic to the surface and to assess the potential for chemical modifications to reduce the adhesion between ice and the pavement surface. The paper also aims to examine the influence the chemical modifications have on the durability of the pavement surface course.

\section{Chemical selection}

The paper considers two potential chemical additions, which have been selected based on their low surface energy and freeze point depressant characteristics. These are sodium formate and sodium silicate. Sodium silicate was determined not to influence the freezing point of water at concentrations below $5 \%$. At a concentration of $10 \%$, sodium silicate marginally reduced the freezing point of water to a value of $-0.5^{\circ} \mathrm{C}$. The freezing point for sodium formate solutions recorded was much lower relative to sodium silicate, with values of $-1 \cdot 2^{\circ} \mathrm{C}$, $-2 \cdot 2^{\circ} \mathrm{C}$ and $-5 \cdot 2{ }^{\circ} \mathrm{C}$ at concentrations of $3 \%, 5 \%$ and $10 \%$, respectively.

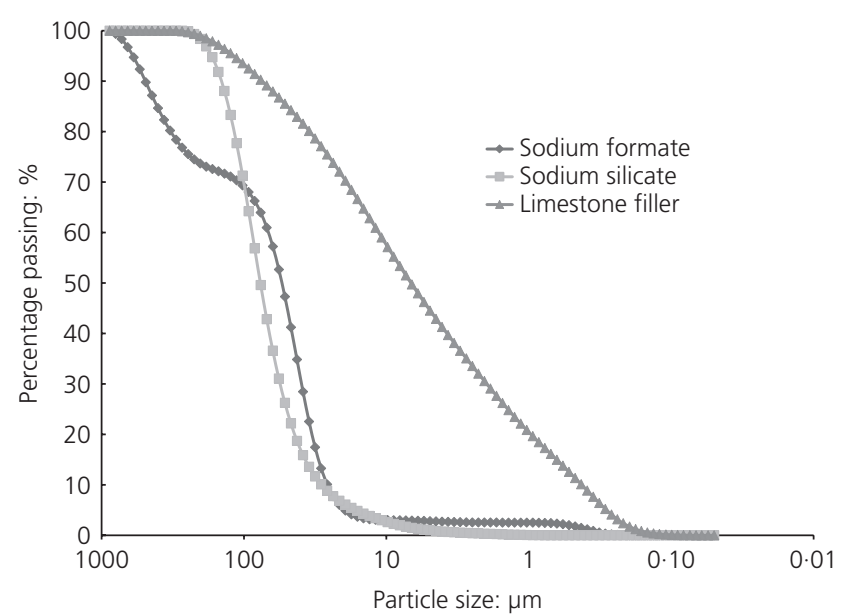

Figure 1. Particle size distribution for chemical additions and limestone filler

For the purpose of this study, sodium formate or sodium silicate were added as a partial filler replacement to form a chemically modified bitumen mastic. The sodium formate and sodium silicate particles used as part of this study have a mean particle size of $55 \mu \mathrm{m}$ and $75 \mu \mathrm{m}$, respectively. The particle size distribution is illustrated in Figure 1.

Limestone filler was utilised for the remainder of the filler. The bitumen used to form the sodium formate mastic and the sodium silicate mastic was a $40 / 60$ penetration grade bitumen. The two mastics were formulated to be volumetrically comparable, comprising $73.9 \%$ bitumen by volume and $26 \cdot 1 \%$ of chemical addition and limestone filler.

\section{Chemical transfer}

In order for the de-icing chemicals to interact with the formation of ice and be effective at reducing ice adhesion they are required to be present at the pavement surface. An evaluation of the chemical transfer in mastics was assessed using scanning electron microscopy (SEM).

SEM is a rapid and non-destructive technique used to investigate the microstructure, morphology and elemental composition of materials. Environmental scanning electron microscopy (ESEM) is a form of SEM enabling imaging and elemental analysis of samples incompatible with high vacuum, such as non-conductive, hydrated and delicate samples.

SEM (Figure 2) uses the following techniques to assess a number of material parameters

- high-resolution secondary electron imaging of topographic surfaces to examine microstructure and particular features such as size and morphology in a sample 
Transport

Volume 169 Issue TR2
Chemical pavement modifications to

reduce ice adhesion

Wright, Parry and Airey

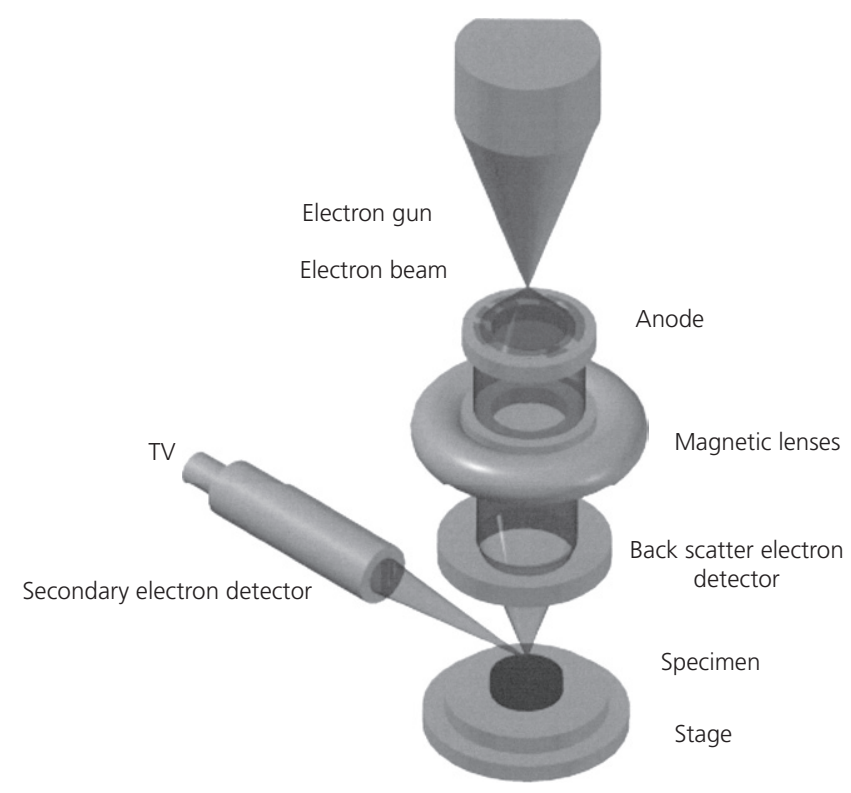

Figure 2. Scanning electron microscope

- backscatter electron imaging for identification of phases with differences in composition

- energy-dispersive X-ray spectroscopy (EDX) analysis to determine elemental composition of morphological and textural features in a sample

- multi-element digital X-ray maps for spatial distribution and relative concentrations of elements.

The ESEM technique utilises a controlled flow of gas into the sample chamber to maintain the pressure at levels much higher than conventional SEM. As part of this technique, water vapour can be introduced to the chamber to produce relative humidity up to $100 \%$. The variable temperature Peltier sample stage can then be used to control evaporation and condensation.

Penn and Meyerson (1992) used SEM to examine the surface roughness of asphalt concrete as part of a study into ice bond prevention on pavement surfaces. ESEM has been used previously by Varanasi et al. (2010) to study frost formation and ice adhesion on superhydrophobic surfaces. The use of ESEM to study the transfer of de-icing chemicals from within a mastic surface is a new concept.

To assess the surface topography and chemical transfer from the mastic in relation to the influence of moisture absorption a cycled conditioning protocol was employed. The relative humidity was increased by increments of $10 \%$ to replicate moisture absorption from $0 \%$ up to $100 \%$ relative humidity. At $100 \%$ relative humidity the sample was fully submerged by adjusting the partial pressure and temperature of the Peltier stage. This was followed by a reverse procedure by decreasing

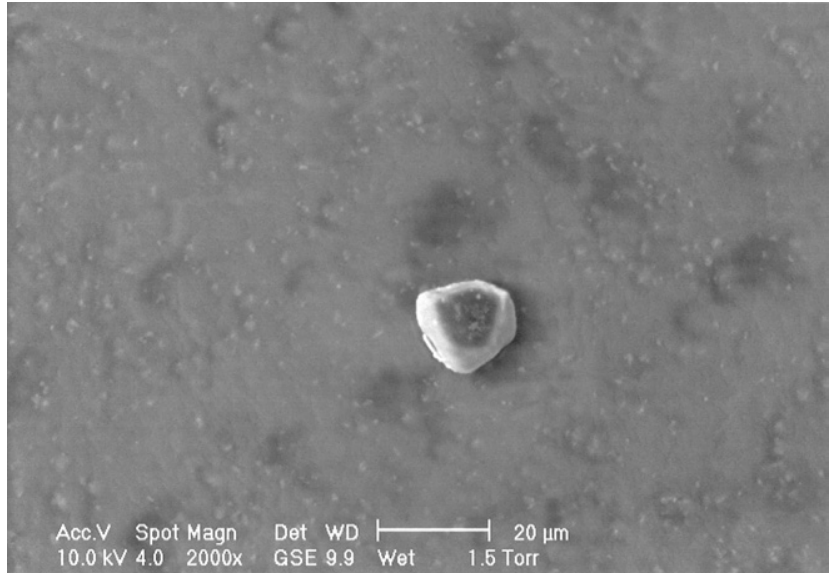

Figure 3. Image of surface topography of mastic before wetting

the relative humidity to dry the specimen and encourage the deposition of the chemical. The conditioning procedure was designed to replicate the full range of relative humidity a pavement surface may experience. This conditioning process was conducted twice for each mastic.

At each $10 \%$ relative humidity increment, specific particles of the chemical additives were imaged to identify the particle features, morphology and elemental composition of the particles. The major elements of interest to this study were sodium and silicon from the chemical formulations. Elemental mapping was employed to determine the spatial distribution of elements before and after wetting to provide an indication of how the particles are mobilised from the mastic and then deposited on the sample surface.

Initial observations of the mastic samples were conducted at a pressure of $0.2 \mathrm{kPa} \quad(1.5$ Torr $)$ at ambient temperature. Observations of the chemically modified mastics identified a relatively flat and smooth surface with numerous particles protruding from the sample surface - see Figure 3.

The particles varied in shape and size and were typically below $20 \mu \mathrm{m}$ in size. Analysis of various particles present at the surface using EDX analysis identified that the particles were typically composed of calcium, carbon and oxygen indicating the presence of the limestone filler - see Figure 4.

Analysis of the background between particles indicates this was primarily composed of carbon, hydrogen and sulfur, which is consistent with the presence of bitumen. Only a very limited number of particles exhibiting the elemental composition of sodium formate or sodium silicate were detected at the surface of the respective mastics. This indicates that the chemical is maintained in the body of the mastic and that a bitumen film covers the sodium formate or sodium silicate particles. To prevent detection using EDX analysis 


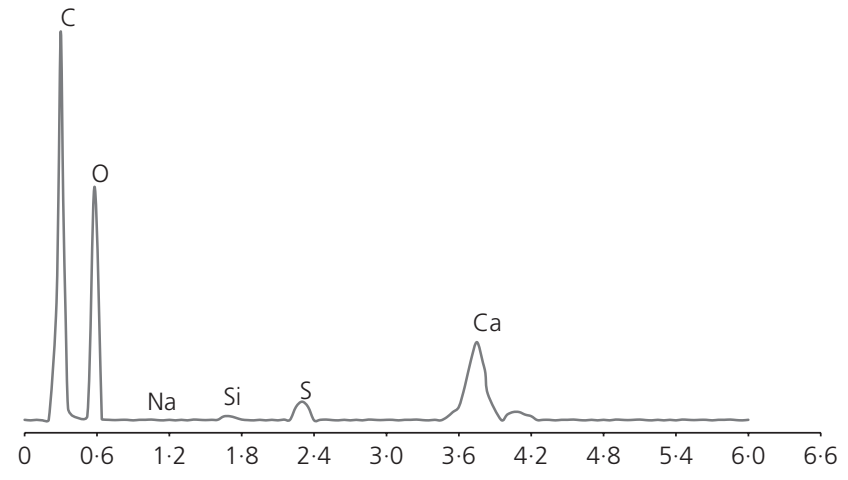

Figure 4. EDX analysis of particles typically detected at the mastic surface before wetting

this bitumen film is likely to be generally at least $5 \mu \mathrm{m}$ in thickness.

The relative humidity was incrementally increased and up to relative humidity of $60 \%$, there was no significant change to the appearance of the particles being imaged. At a relative humidity of $60 \%$ there were initial signs of wetting on the sodium formate and sodium silicate mastics, as signified by a discrete dark region defining a water droplet - see Figure 5.

With increasing relative humidity the number of water droplets increased with the wetted area, spreading to cover a wider area. This was particularly evident around sodium formate particles above a relative humidity of $70 \%$. When $100 \%$ relative humidity had been achieved, the surface of each mastic was fully wetted with a thin layer of water, preventing any observation of the surface and defined droplets present on the mastic surface - see Figure 6.

The relative humidity was then decreased and as the humidity fell below $60 \%$ the first sign of defined particles emerged at the surface of the mastic where a water droplet had previously been. As the humidity decreased, further the particles continued to dry and the structure became visible. Observations of the particles demonstrated the following.

- Sodium formate mastic. The particles were of an angular spikey appearance, on occasions originating from a central point and typically in excess of $200 \mu \mathrm{m}$ in size, see Figure 7. These particles displayed strong peaks of the element sodium when subjected to EDX analysis - see Figure 8.

- Sodium silicate mastic. The particles appeared in general to be smooth and well-defined in the region of 50-100 $\mu \mathrm{m}$ in size, see Figure 9. Strong sodium, silicon and oxygen signals were produced from the EDX analysis - see Figure 10.

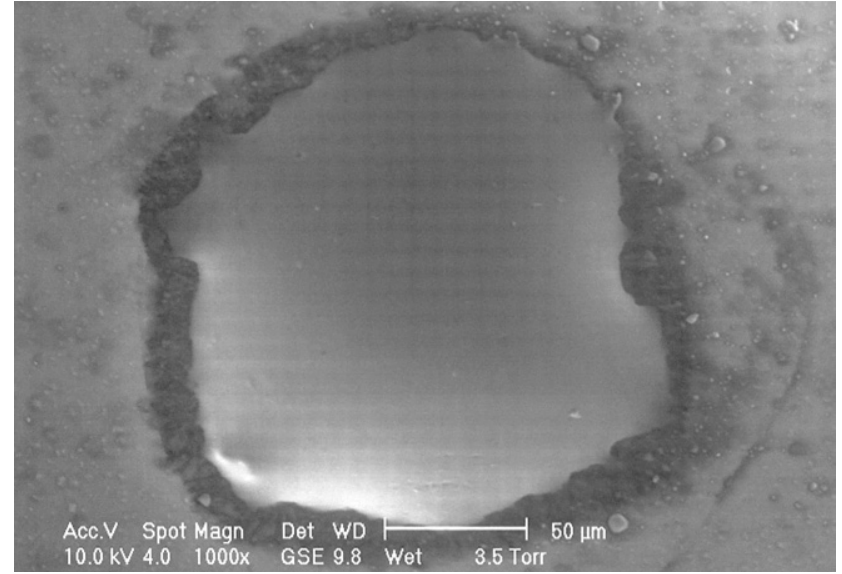

Figure 5. Water droplet forming on the sodium formate mastic surface

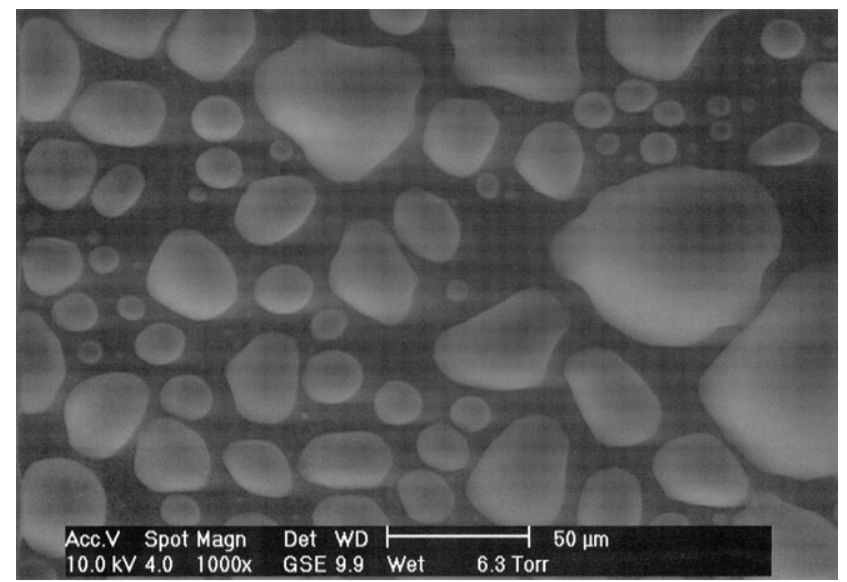

Figure 6. Overview of the sodium formate mastic surface at $100 \%$ relative humidity

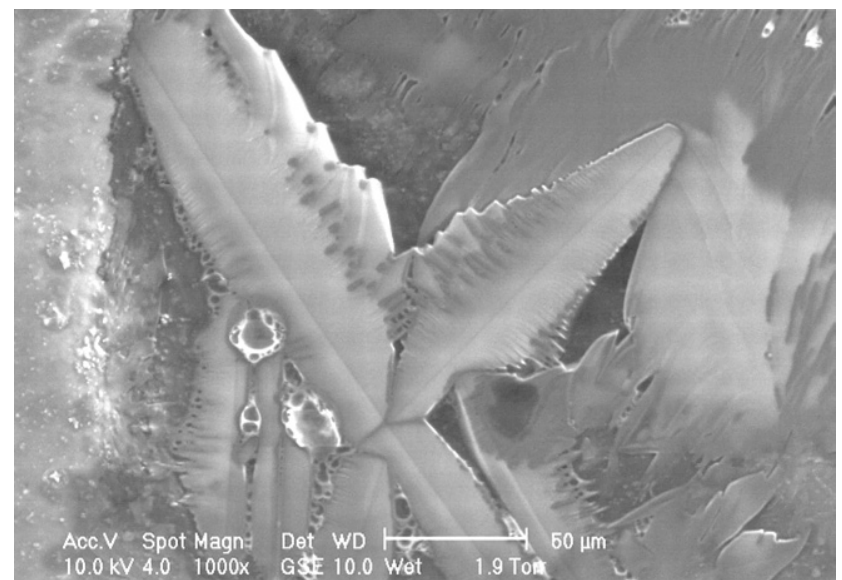

Figure 7. Example of angular crystalline formation of deposited sodium formate 


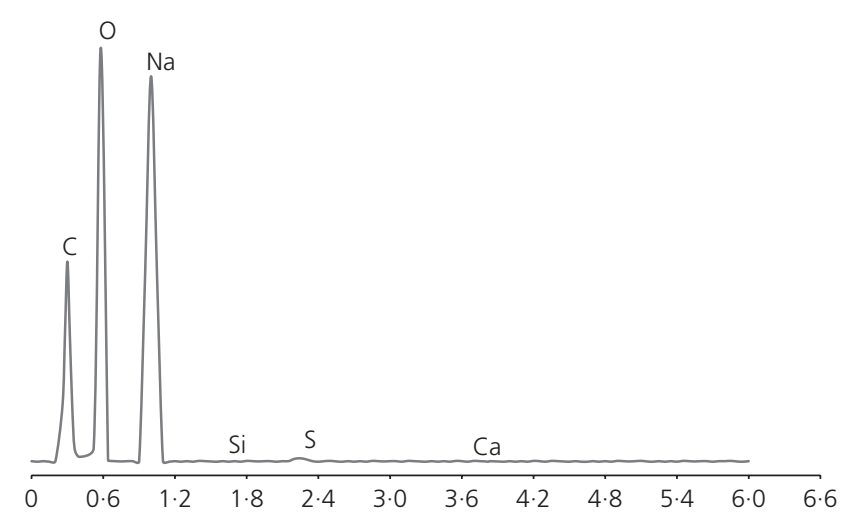

Figure 8. EDX analysis of sodium formate particle

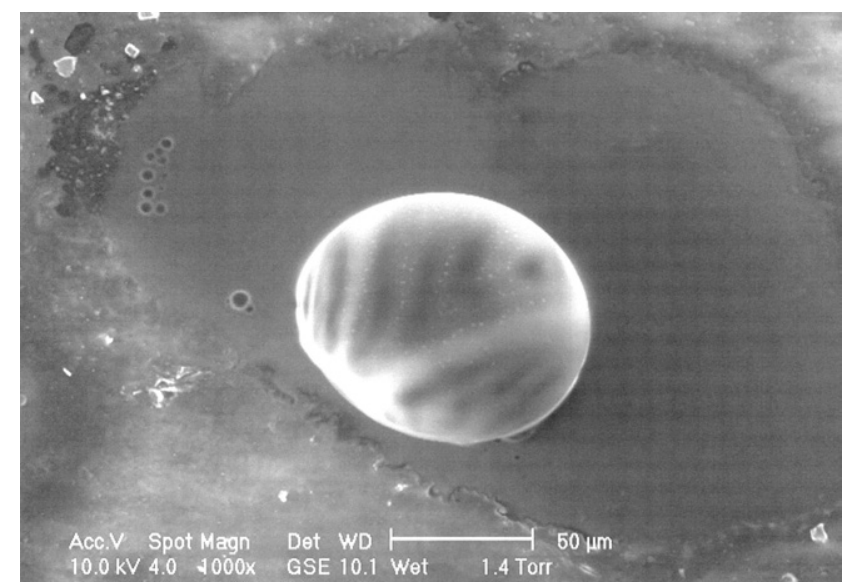

Figure 9. Structure of deposited sodium silicate particles

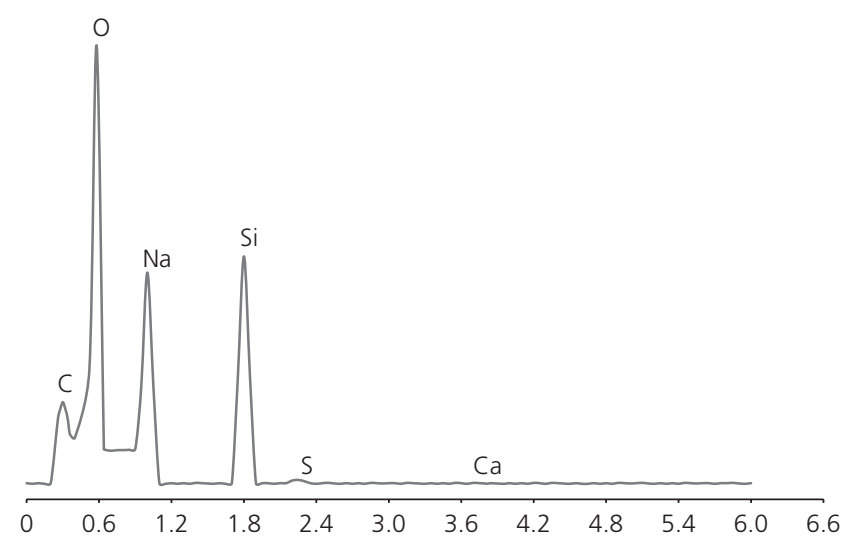

Figure 10. EDX analysis of sodium silicate particle

The first cycle of this phase of testing demonstrates that both sodium formate and sodium silicate particles are typically not present at the mastic surface, but can be transferred through a bitumen film to the surface of the respective mastic as the

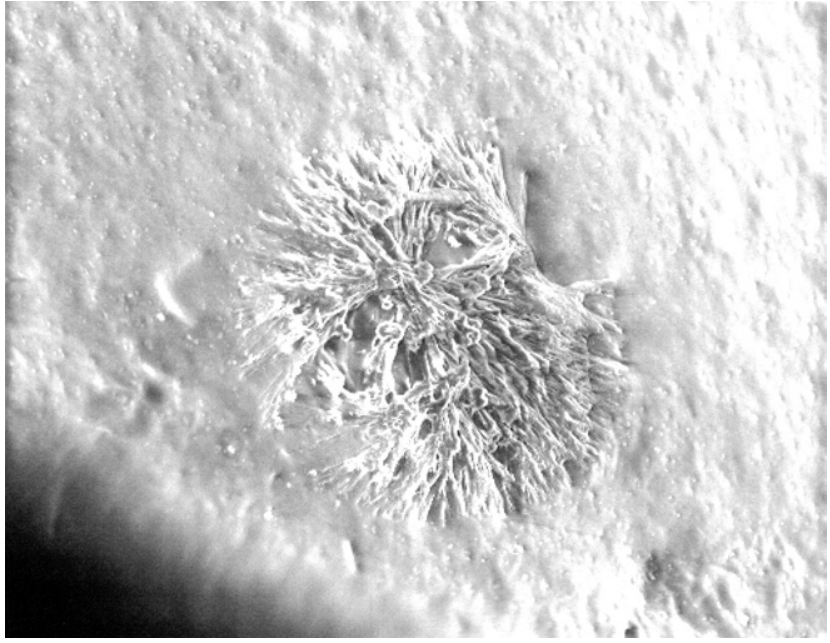

Figure 11. Image of initial exposed particle after cycle 1

humidity increases. This transfer occurs at high relative humidity under the presence of moisture. On reducing the humidity, the individual particles are deposited or dispersed over a proportion of the mastic surface.

The level of relative humidity was increased once more at $10 \%$ increments through changes in temperature and pressure. Up until a relative humidity of $60 \%$ there was no significant change to the appearance of the particles being imaged. At a relative humidity of $60 \%$ the initial wetting of a number of sodium formate particles and the majority of sodium silicate particles was observed as they absorbed moisture. At $70 \%$ relative humidity all of the particles of sodium formate were demonstrating some form of wetting, with increasing intensity and spreading of the wetted area. At relative humidities of $80 \%$ there was full water coverage for all de-icing chemical particles identified.

The relative humidity was again decreased with chemical particles being deposited on the surface with clearly defined structures in a similar manner to the first cycle. Topographical assessments were made of the particles deposited. Elemental spatial distribution was conducted for individual particles exposed after conditioning cycle 1 and comparisons made to the distribution after conditioning cycle 2 .

A number of sodium formate or sodium silicate particles demonstrated relatively limited changes in the spatial distribution after being exposed from cycle 1 (Figure 11) and redeposited after cycle 2 (Figure 12).

These particles maintained a strong sodium response around the centre of the original particle, with smaller discrete particles being transferred from the centre or forming through the mastic - see Figures 13 and 14. 


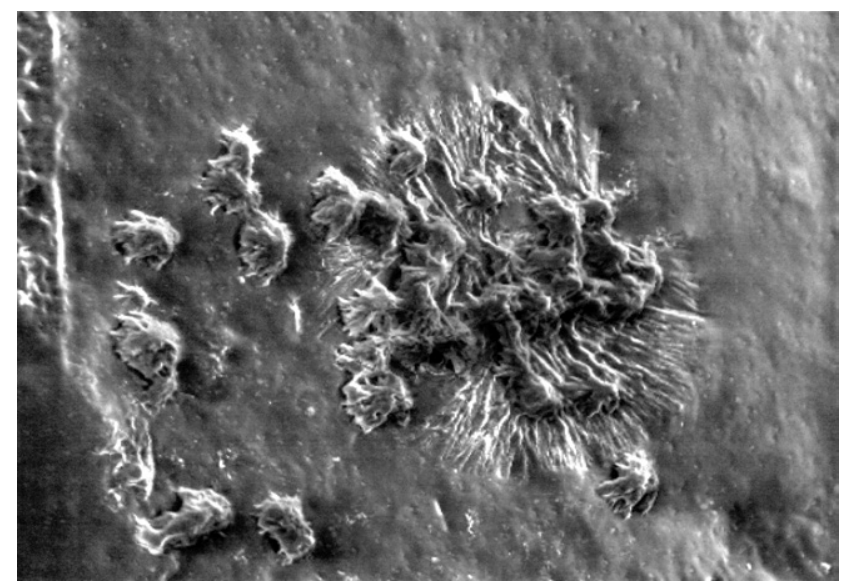

Figure 12. Image exposed particle after conditioning cycle 2

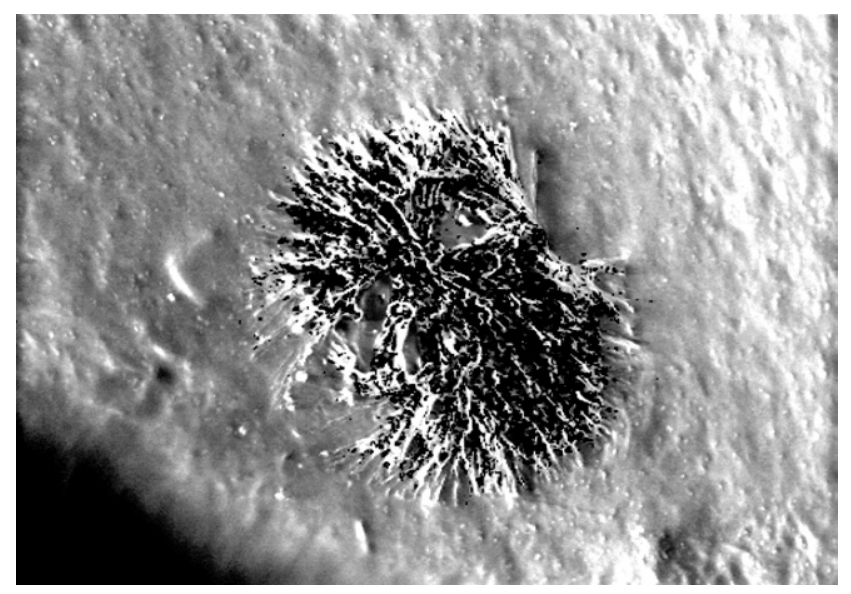

Figure 13. Filter overlay of sodium element with initial exposed particle after cycle 1

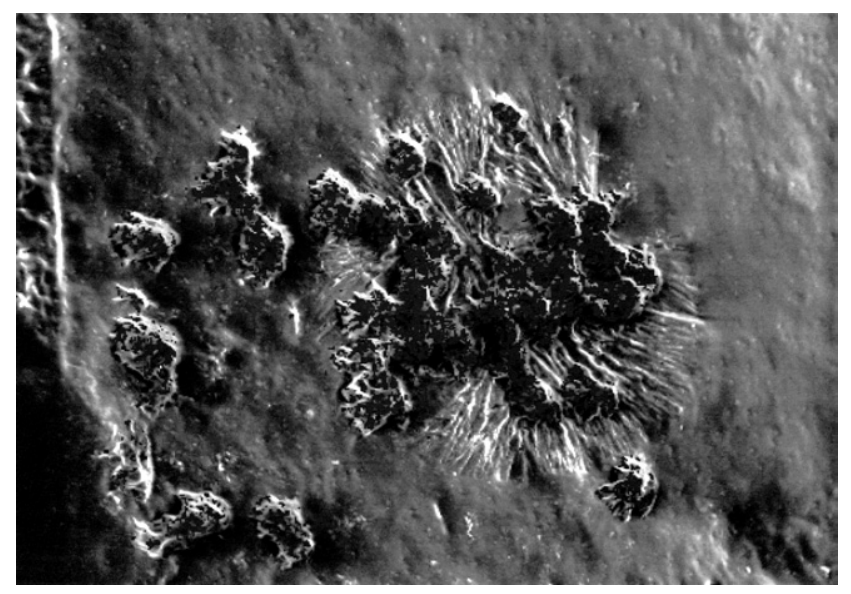

Figure 14. Filter overlay of sodium element of exposed particle after conditioning cycle 2
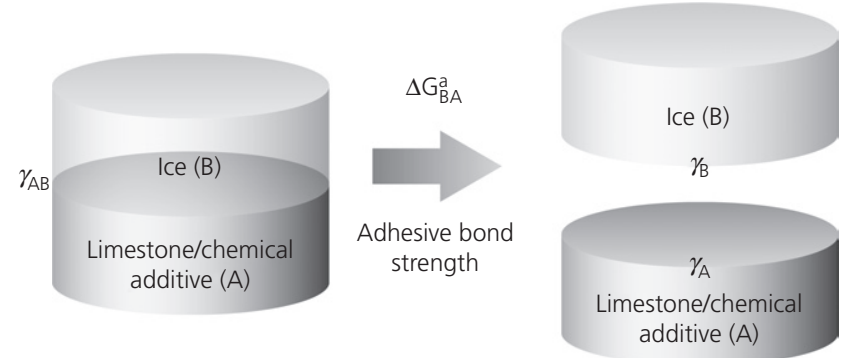

Figure 15. Work of adhesion

It is observed that the chemicals can be effectively transferred and maintained at the mastic surface. The presence of such chemicals at the surface indicates that they could transfer from the mastic of a pavement surface course and influence the adhesion between ice and the pavement surface.

\section{Ice bond strength - work of adhesion}

Surface energy is commonly used to predict adhesion between two materials. Creation of a low-energy surface is an approach widely investigated for de-icing purposes on ships, leading edges of airplane wings and overhead telephone wires. In order to lower the ice adhesion as much as possible, surface energy components must be made as small as possible. The lower these values, the lower the overall forces that hold the ice to the surface will be, and the more easily it can be removed (Figure 15).

The adhesion between two surfaces can be calculated from the surface energy parameters of individual materials, which meet to form an interface. As part of this study the surface energy was measured for the de-icing chemicals using the Washburn method. The surface energy parameters of limestone filler were measured using dynamic vapour sorption (DVS). DVS is a technique developed to measure the surface energy of high surface area solids, such as fillers (Levoguer and Williams, 2003).

Work of adhesion calculations were then conducted to establish if the de-icing chemicals can weaken the adhesion between ice and a modified surface and theoretically allow easier removal of ice from the pavement surface.

Several theories explain the molecular origin of surface free energy of solids. The Good-Van Oss-Chaudhury theory is widely applied to explain the surface free energy components of various materials and determine these components by measuring work of adhesion of the material with other liquids or vapours (Bhasin, 2006).

According to the Good-Van Oss-Chaudhury theory, the total surface free energy of any material is divided into three 
components based on the type of molecular forces on the surface. These components are

- the non-polar component, also referred to as the Lifshitz-

Van der Waals (LW) or the dispersive component

- the Lewis acid component (polar component)

- the Lewis base component (polar component).

The total surface free energy $(\gamma)$ is obtained by combining these components as follows

1. $\gamma=\gamma^{\mathrm{LW}}+\gamma^{\mathrm{AB}}$

where $\gamma^{\mathrm{LW}}$ is the Lifshitz Van der Waals component and $\gamma^{\mathrm{AB}}$ is the acid/base (polar) component which comprises the Lewis acid $\gamma^{+}$and the Lewis base $\gamma^{-}$components

2. $\gamma^{\mathrm{AB}}=2 \sqrt{\gamma^{+} \gamma^{-}}$

The Lifshitz Van der Waals and the Lewis acid and Lewis base components were measured using various techniques dependent upon the material properties and are presented in Table 1.

The surface energy parameters of ice used for the calculation were $\gamma^{\mathrm{LW}}=29.6 \mathrm{~mJ} / \mathrm{m}^{2}, \quad \gamma^{+}=14 \mathrm{~mJ} / \mathrm{m}^{2}$ and $\gamma^{-}=28 \mathrm{~mJ} / \mathrm{m}^{2}$ based on research conducted by Van Oss et al. (1992).

According to Good-Van Oss-Chaudhury theory, the adhesive bond strength, $\Delta G_{\mathrm{BA}}^{\mathrm{a}}$, between two materials 'A' and 'B' can be computed in terms of their respective surface free energy components by

3. $\Delta G_{\mathrm{BA}}^{\mathrm{a}}=2 \sqrt{\gamma_{\mathrm{B}}^{\mathrm{LW}}+\gamma_{\mathrm{A}}^{\mathrm{LW}}}+2 \sqrt{\gamma_{\mathrm{B}}^{+}+\gamma_{\mathrm{A}}^{-}}+2 \sqrt{\gamma_{\mathrm{B}}^{-}+\gamma_{\mathrm{A}}^{+}}$

Based on the surface energy parameters established and the above principles, the work of adhesion between ice and limestone fillers/chemical additives has been calculated, where A denotes limestone or the chemical additive and $\mathrm{B}$ represents ice. These are presented in Table 2.

Surface energy component: $\mathrm{mJ} / \mathrm{m}^{2}$

\begin{tabular}{lrrrr}
\cline { 2 - 5 } & \multicolumn{1}{c}{$\gamma^{\mathrm{LW}}$} & \multicolumn{1}{c}{$\gamma^{\mathrm{AB}}$} & \multicolumn{1}{c}{$\gamma^{+}$} & \multicolumn{1}{c}{$\gamma^{-}$} \\
\hline Limestone filler & 55.3 & 191.6 & 51.6 & 178.1 \\
Sodium formate & 15.1 & 11.7 & 2.8 & 12.4 \\
Sodium silicate & 16.3 & 6.9 & 1.8 & 6.7
\end{tabular}

Table 1. Surface energy components of reference materials

\begin{tabular}{lcc}
\hline & $\begin{array}{c}\text { Calculated work of } \\
\text { adhesion with } \\
\text { ice: } \mathrm{mJ} / \mathrm{m}^{2}\end{array}$ & $\begin{array}{c}\text { Reduction in ice } \\
\text { adhesion relative to } \\
\text { limestone filler: \% }\end{array}$ \\
\hline Limestone filler & 257 & - \\
Sodium formate & 77 & 70 \\
Sodium silicate & 86 & 67 \\
Table 2. Calculated work of adhesion between limestone \\
filler/chemical additives and ice
\end{tabular}

The high surface energy properties of limestone filler indicate that a strong adhesion would be achieved with ice. The test results demonstrate that the low surface energy properties of sodium formate and sodium silicate substantially reduced the theoretical adhesion with ice by $70 \%$ and $67 \%$, respectively.

The surface energy properties of the limestone filler are consistent with other limestone aggregates tested and typically higher than granite aggregates used in bituminous mixtures (Ahmad, 2011). The calculation results demonstrate that if the chemical particles are transferred to the pavement surface as observed in the ESEM testing, then the bond achieved between ice and the chemical particles will be significantly less, relative to the bond between ice and aggregate filler particles. Theoretically this will allow for easier ice removal under trafficking.

\section{Physical measurement of ice bond strength}

In order to further examine the potential ice bond strength reduction, physical bond strength measurements were undertaken. Currently there is no standard method for measuring ice adhesion to a bituminous surface. A modified torque bond experiment was therefore developed to assess the ice bond strength in terms of the torque required to fully break the interfacial bond between the bituminous mastic and an ice disc.

The equipment used for this research was a specifically designed testing rig that comprised a fixed base for holding the bituminous sample and a freely rotating upper component with a pre-bonded ice disc. The ice bond strength was measured using a hand-held torque meter. The equipment and set-up are shown in Figure 16 and Figure 17.

Chemical solutions were manufactured at total concentrations of 1,3 and $5 \%$ by weight for the various formulations. Formulations were $100 \%$ sodium formate (100SF), $100 \%$ sodium silicate (100SS) and 50/50 and 70/30 formulations of the two. These were then poured into a metal test head cylinder and frozen at $-20^{\circ} \mathrm{C}$ for a minimum of $12 \mathrm{~h}$. 


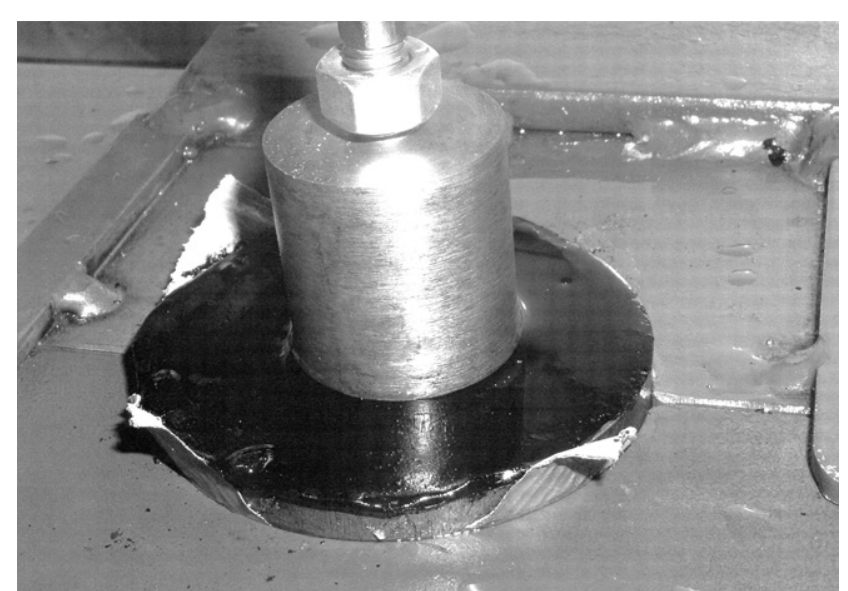

Figure 16. Photograph of ice bond equipment set-up

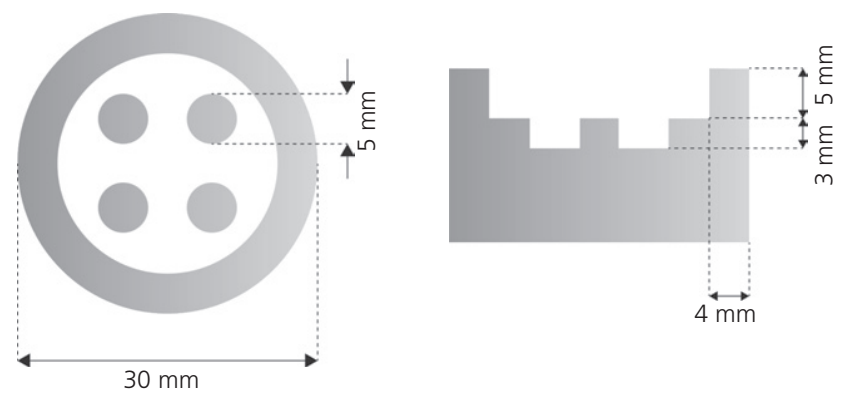

Figure 17. Schematic diagram of test head and dimensions

The test heads were specially designed with a notched insert (as shown in Figure 17) to ensure the ice disc created inside could not rotate or move in any way. At the same time a bitumen mastic disc was frozen at $-20^{\circ} \mathrm{C}$ for a minimum of $12 \mathrm{~h}$, placed and secured to the base of the testing equipment. The two components were then bonded together by placing $5 \mathrm{ml}$ of the solution on the bitumen mastic disc and lowering the ice disc onto the bitumen surface. The entire unit was then frozen at various temperatures for a period of $45 \mathrm{~min}$ and the ice bond strength measured using the torque meter.

The bond established between ice and a material surface is a complex function dependent on temperature, rate and direction of freezing, and the physical and chemical conditions of the substrate surface. Special attention was therefore given to ensure samples and the test procedure conditions were constant and that no external variables were introduced.

The mean ice bond strength was calculated based on five measurements for each de-icing solution at 1\%, 3\% and 5\% concentrations between $-1{ }^{\circ} \mathrm{C}$ to $-5^{\circ} \mathrm{C}$. These results are presented in Figures 18-20. The error bars displayed represent \pm 1 standard deviation.
The results demonstrate a reduction in the bond strength between all of the de-icing chemical solutions and the bitumen mastics' surface in comparison to the bond strength between water (control) and the bitumen surface. This difference becomes more evident as the chemical concentration is increased from $1 \%$ to $5 \%$.

The following observations can be made

a a $1 \%$ concentration the de-icing chemicals solutions have bond strength with bitumen which is typically $2 \cdot 5-14 \cdot 6 \%$ less than the bond strengthen with water

- at a $3 \%$ concentration the de-icing chemicals solutions are more effective, with reductions ranging from $5 \cdot 4-24 \cdot 8 \%$ less than for water.

- at $5 \%$ concentration the bond strength measured is up to $46.8 \%$ less than for water; at a test temperature of $-5^{\circ} \mathrm{C}$ the control water sample bond strength increased but the de-icing chemical bond strengths remained constant.

This confirms that the chemicals can weaken the bond and that the bond strength is directly related to the amount of deicing chemical that can be transferred. Generally, the results for sodium formate and sodium silicate are similar across all temperatures and concentrations with sodium formate generally producing the lowest bond strengths. This appears consistent with the theoretical work of adhesion calculations and highlights the effect that low surface energy materials can have on bond strength. The lower freezing point of sodium formate solution may also influence the bond strength measured.

Overall, the testing confirms that the inclusion of lower surface energy de-icing chemicals can weaken the bond between ice and a bituminous surface and confirms that work of adhesion calculations provide a good estimate for highlighting potentially effective chemicals. The test method developed has proved to be an accurate method of measuring ice bond strength in the laboratory with an average standard deviation of less than $0 \cdot 2 \mathrm{~N} / \mathrm{mm}^{2}$ over 324 individual tests.

\section{Influence of surface energy on moisture sensitivity}

Moisture damage can be defined as the loss of strength and durability in asphalt mixtures owing to the effects of moisture (Little et al., 2003). The presence of water (or moisture) often results in premature failure of pavements in the form of isolated distress caused by debonding of the bitumen film from the aggregate surface, referred to as stripping, and/or early rutting/fatigue cracking owing to reduced mixture strength (Lu et al., 2007).

Surface energy and the impact on the moisture sensitivity of mixes has been widely examined. The incorporation of low surface energy materials can be detrimental to the durability performance of asphalt (Ahmad, 2011; Bhasin, 2006). 


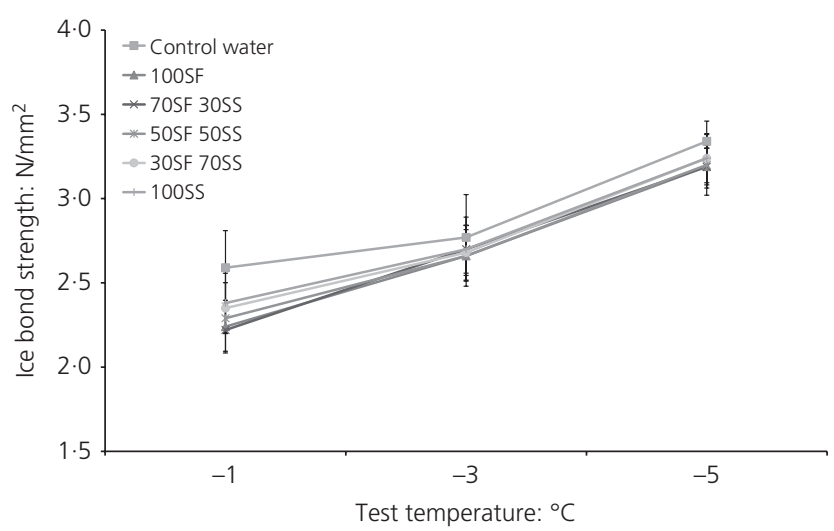

Figure 18. Mean ice bond strength at a $1 \%$ concentration

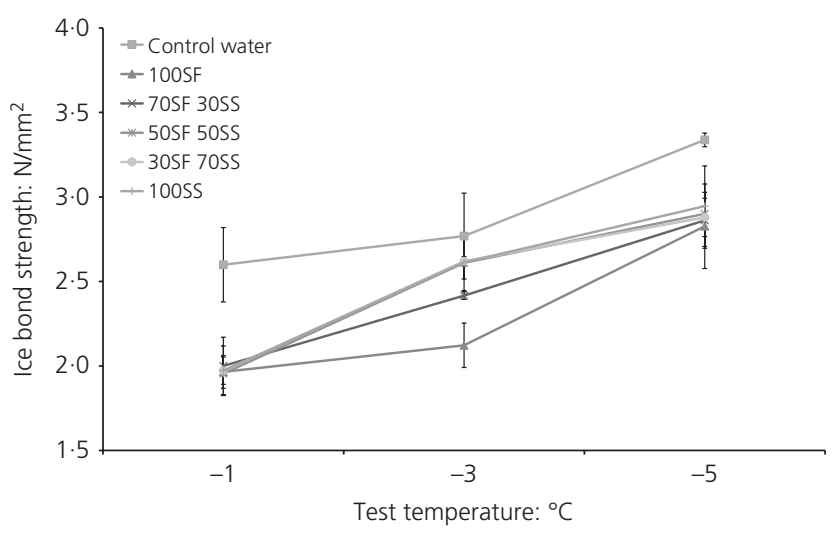

Figure 19. Mean ice bond strength at a 3\% concentration

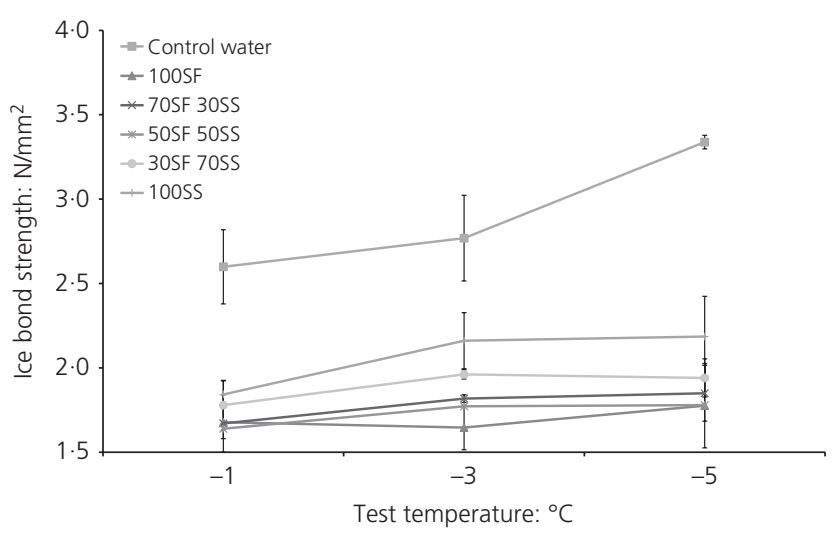

Figure 20. Mean ice bond strength at a $5 \%$ concentration

Binder affinity testing on coated particles and water sensitivity of chemically modified asphalt was therefore conducted to examine the susceptibility of mixtures containing the deicing chemical formulations to moisture damage.

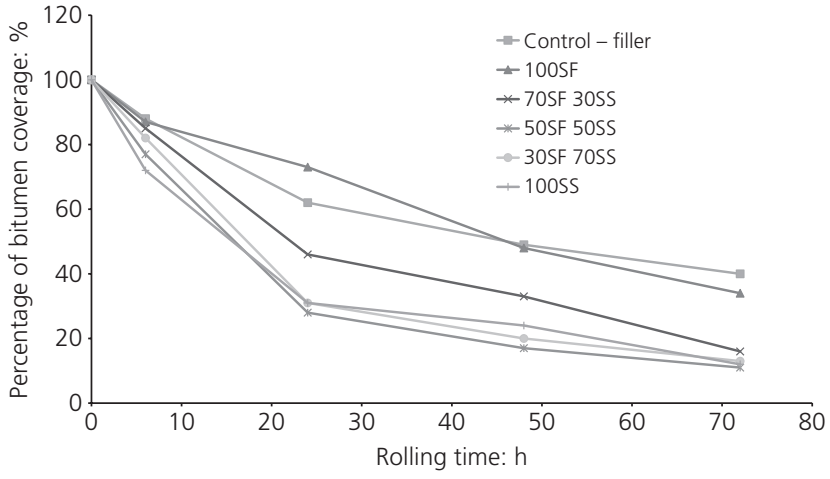

Figure 21. Percentage of bitumen coverage against time for each de-icing chemical formulation

\subsection{Binder affinity testing}

Binder and aggregate/filler combinations with a tendency to strip are said to have low binder affinity. The tendency for stripping of the binder film in the presence of water is highly correlated to the surface properties of the binder, aggregate and filler. Binder affinity testing was conducted in accordance with Section 6.3.5 of BS EN 12697-11:2005 (BSI, 2005) Rolling bottle method. The test method was selected because it provides a measure of binder affinity over specific time periods to indicate the rate at which stripping occurs.

Test samples were prepared by washing and drying a single size fraction of $6 \cdot 3 / 10 \mathrm{~mm}$ aggregate. The filler or de-icing chemicals were then added to the aggregate at a rate of $3 \%$ by mass to the aggregate and coated with bitumen to obtain individual uniformly coated particles.

A sample of the coated particles was transferred to bottles filled with deoinised water at $5^{\circ} \mathrm{C}$. The bottles were then sealed and rolled at $60 \mathrm{r} / \mathrm{min}$ at ambient temperature for defined time periods, these were 6, 24, 48 and $72 \mathrm{~h}$. At these specific time intervals, the degree of bitumen coverage on the aggregate particles was visually estimated. The mean bitumen coverage over time for the various de-icing chemical additions is presented in Figure 21.

The test results demonstrated reduced binder affinity in the presence of sodium silicate. A substantial reduction in retained bitumen coverage was evident when sodium silicate was incorporated in the mixture after being rolled for a period of $24 \mathrm{~h}$. The binder affinity test result for the sodium formate sample (100SF) was broadly comparable to the limestone filler control sample.

\subsection{Water sensitivity testing}

A test to determine asphalt specimens' sensitivity to water was conducted in accordance with BS EN1297-12:2003 (BSI, 2003a). This test assesses the effect of saturation and 
accelerated water conditioning on the indirect tensile strength of asphalt specimens. The chemical modification was added to the asphalt at $3 \%$ by mass using formulations consistent with the previous experiment.

The test procedure required six cylindrical specimens to be manufactured per formulation using impact compaction in accordance with BS EN 12697-30:2004 (BSI, 2004). The six specimens were then divided into two equally sized subsets having approximately the same average dimensions and bulk density. One subset is maintained dry in a temperature-controlled cabinet at $20^{\circ} \mathrm{C}$, whereas the other subset is saturated and stored in water at an elevated conditioning temperature of $40 \pm 1^{\circ} \mathrm{C}$ for a period of 68 to $72 \mathrm{~h}$.

After conditioning, the wet specimens were brought to the test temperature of $20^{\circ} \mathrm{C}$ for a minimum of $2 \mathrm{~h}$. The indirect tensile strength was then determined for both the dry and wet subsets in accordance with BS EN 12697-23:2003 (BSI, 2003b). The indirect tensile strength of the water conditioned subset is compared to that of the dry subset to calculate the indirect tensile strength ratio, and is expressed as a percentage. The tests results are presented in Table 3.

The test results demonstrate that the $100 \%$ sodium formate addition, produced comparable indirect tensile strength ratios relative to the control specimens. All de-icing chemical formulations which included sodium silicate were highly sensitive to water with a significantly lower percentage of strength retained. The inclusion of even small amounts of sodium silicate could be detrimental to the durability of the asphalt.

\section{Conclusions and recommendations}

ESEM testing has demonstrated that de-icing chemicals incorporated into a bituminous mastic as a filler replacement can be transferred to the mastic surface owing to moisture absorption at relatively high humidity.

A repeatable ice bond strength test has been developed. When specific de-icing/low surface energy chemicals, sodium formate and sodium silicate, are present in frozen water solutions, a substantial reduction in bond strength between the bitumen mastic and ice has been measured relative to water alone. This is consistent with surface energy measurements. The reduction in bond strength generated by chemical modifications could lead to easier removal of ice from chemically treated asphalt.

Durability testing of asphalt containing the specific de-icing/ low surface energy chemicals demonstrated variable results when subjected to water sensitivity testing. Increased susceptibility to deterioration in the presence of water was evident when sodium silicate was incorporated into the bituminous mixture. Sodium formate modifications did not show a reduction in performance relative to the control specimens, despite the low surface energy of this chemical. This difference could be associated with the high surface texture and specific surface area $\left(0.202 \mathrm{~m}^{2} / \mathrm{g}\right)$ of sodium formate particles, resulting in a greater adhesive bond with bitumen. In contrast, sodium silicate has a smooth texture and a lower specific surface area of $0.005 \mathrm{~m}^{2} / \mathrm{g}$, which may result in a poor adhesive bond with bitumen.

The study has demonstrated that specific low surface energy materials can be incorporated into pavement surface course to reduce the adhesion between ice and the pavement surface, thereby allowing the ice to be easily removed. It is recommended that further research is conducted to screen low surface energy chemicals, which reduce ice adhesion without influencing the water sensitivity and durability of the asphalt. It is recommended that a detailed study is conducted on promising chemicals to further examine the durability of pavement surfaces incorporating such chemical modifications. Furthermore, it is recommended that alternative ways of incorporating or applying low surface energy materials into pavement surface courses are explored. Such alternative methods may consider introducing adhesion agents to mitigate the durability problems when incorporating specific low surface energy material as filler, incorporating the low surface energy materials into surface treatments or applying the low surface energy material as a coating to the pavement surface.

\begin{tabular}{lccc}
\hline Asphalt formulation & $\begin{array}{c}\text { Average indirect tensile } \\
\text { strength - dry subset: kPa }\end{array}$ & $\begin{array}{c}\text { Average indirect tensile } \\
\text { strength - wet subset: kPa }\end{array}$ & $\begin{array}{c}\text { Retained indirect tensile } \\
\text { strength: \% }\end{array}$ \\
\hline Control & 1571 & 1334 & $84 \cdot 86$ \\
$3 \%$ 100SF & 1317 & 1074 & $81 \cdot 53$ \\
$3 \%$ 70SF 30SS & 1347 & 865 & $64 \cdot 22$ \\
$3 \%$ 50SF 50SS & 1424 & 839 & $58 \cdot 95$ \\
$3 \%$ 30SF 70SS & 1357 & 821 & $60 \cdot 48$ \\
$3 \%$ 10OSS & 1299 & 590 & $45 \cdot 46$
\end{tabular}

Table 3. Water sensitivity of asphalt specimens in accordance

with BS EN 12697-12:2003 (BSI, 2003a) 
This study has focused on the initial reduction in the bond strength between ice and a modified pavement surface course. It is likely that concentration of de-icing chemicals at the pavement surface will reduce over time owing to the influence of traffic and surface water run-off due to precipitation. It is recommended that further research is conducted relating to the longevity of such modifications and to quantify the anti-icing performance over time. It is recommended that this future research considers influencing factors including air void content of the pavement surface, trafficking, climatic conditions such as precipitation, de-icing chemical and chemical concentration.

\section{REFERENCES}

Ahmad N (2011) Asphalt Mixture Moisture Sensitivity Analysis Using Surface Energy. PhD thesis, The University of Nottingham, Nottingham, UK.

Avery R (1973) Some effects of de-icing chemicals on roadside trees. Highway Research Record 425: 14-16.

Backman L and Folkeson L (1996) Influence of de-icing salt on vegetation, groundwater and soil along two highways in Sweden. Proceedings of the 4th International Symposium on Snow Removal and Ice Control Technology, Reno, Nevada, USA, pp. 111-120.

Baum B, White R and Thoma L (1992) Ice-Pavement Bond Prevention: Surface Modification. Strategic Highway Research Program, National Research Council, Washington, DC, USA, SHRP-W/UIR-92-603.

Bhasin A (2006) Development of Methods to Quantify Bitumen-Aggregate Adhesion and Loss of Adhesion Due to Water. $\mathrm{PhD}$ thesis, Texas A\&M University, College Station, TX, USA.

BSI (2003a) BS EN 12697-12:2003: Bituminous mixtures. Test methods for hot mix asphalt - determination of the water sensitivity of bituminous specimens. British Standards Institution, London, UK.

BSI (2003b) BS EN 12697-23:2003: Bituminous mixtures. Test methods for hot mix asphalt: indirect tensile strength. British Standards Institution, London, UK.

BSI (2004) BS EN 12697-30:2004: Bituminous mixtures. Test methods for hotmix asphalt: specimen preparation by impact compactor. British Standards Institution, London, UK.

BSI (2005) BS EN 12697-11:2005: Bituminous mixtures. Test methods for hot mix asphalt: determination of the affinity between aggregate. British Standards Institution, London, UK.

Burtwell M (2004) De-icing trials on UK roads. Performance of prewetted salt spreading and dry salt spreading Proceedings of the 6th International Symposium on Snow Removal and Ice Control Technology, Spokane, Washington, USA. Transportation Research Board, Washington, DC, USA, Transportation Research Circular Number E-C063, pp. $529-540$.
COST (2002) Improvements to Snow and Ice Control on European Roads and Bridges. European Cooperation in the field of Scientific and Technical Research, Ljubljana, Slovenia, COST 344.

D'Itri FM (1992) Chemical Deicers and the Environment. Lewis Publishing, Boca Raton, FL, USA.

Evans M (2012) NSSRG Phase 2 - Summary Report. Transport Research Laboratory, Crowthorne, UK, Client Project Report CPR 726.

Evans M, Morosiuk K and Peeling J (2012) Extreme Cold Solutions. Transport Research Laboratory, Crowthorne, UK, Publish Project Report PPR 624.

Goodwin LC (2002) Analysis of weather-related crashes on US highways. Weather 2(32): 4-64.

Hanke H and Levin C (1988) Influence of Winter Road Maintenance on Traffic Safety and Transport Efficiency. Darmstadt Technical University, Damstadt, Germany (in German).

Kuemmel DA and Hanbali RM (1992) Accident Analysis of Ice Control Operations. Marquette University, Milwaukee, WI, USA, Final Report.

Levoguer CL and Williams DR (2003) Dynamic Vapour Sorption Application Note 17, Measurement of the Surface Energies of Pharmaceutical Powders using a Novel Vapour Adsorption Method. Surface Measurement Systems Ltd, London, UK.

Little D, Cheng D, Lytton R and Holste J (2003) Moisture damage evaluation of asphalt mixture by considering both moisture diffusion and repeated load conditions. Transportation Research Record 1832: 42-49.

Lu Q, Harvey JT and Monismith CL (2007) Investigation of Conditions for Moisture Damage in Asphalt Concrete and Appropriate Laboratory Test Methods: Summary Report. Institute of Transportation Studies, University of California, Davis, CA, USA, Research Report UCDITS-RR-07-45.

Penn L and Meyerson A (1992) Ice-Pavement Bond Prevention: Fundamental Study. Strategic Highway Research Program, National Research Council, Washington, DC, USA, SHRP-W/UFR-92-606.

PIARC (2013) Impact of Changes in Weather Severity on Winter Maintenance. Technical Committee B.5 - Winter Service, PIARC, Paris, France, p. 41.

PIARC (2014) Snow and Ice Databook 2014. Technical Committee 2.4 - Winter Maintenance, PIARC, Paris, France, p. 223.

Quarmby D, Green C and Smith B (2010) The Resilience of England's Transport System in Winter. An Independent Review, Final Report. Department for Transport, London, UK.

RLG (Road Liaison Group) (2014) Well-Maintained Highways. Code of Practice for Highway Maintenance Management. The Stationery Office, London, UK.

Schraufnagel F (1973) Pollution aspects associated with chemical de-icing. Highway Research Record 193: 22-33. 
Strong CK, Ye Z and Shi X (2010) Safety effects of winter weather: the state of knowledge and remaining challenges. Transport Reviews 30(6): 677-699.

Thornes JE (2000) Road salting - an international benefit/ cost review. In Proceedings of the 8th World Salt Symposium (Geertman RM (ed.)). Elsevier, Amsterdam, the Netherlands, pp. 787-792.

Usman T, Fu L and Miranda-Moreno LF (2010) Quantifying safety benefit of winter road maintenance: accident frequency modeling. Accident Analysis \& Prevention 42(6): 1878-1887.

Van Oss CJ, Giese RF, Wentzek R, Norris J and Chulivin EM (1992) Surface tension parameters of ice obtained from positive and negative particle adhesion to advancing freezing fronts. Journal of Adhesion Science Technology 6(4): 503-516. Varanasi K, Deng T, Smith J, Hsu M and Bhate N (2010) Frost formation and ice adhesion on superhydrophobic surfaces. Applied Physics Letters 97(1): 3.

\section{WHAT DO YOU THINK?}

To discuss this paper, please email up to 500 words to the editor at journals@ice.org.uk. Your contribution will be forwarded to the author(s) for a reply and, if considered appropriate by the editorial panel, will be published as discussion in a future issue of the journal.

Proceedings journals rely entirely on contributions sent in by civil engineering professionals, academics and students. Papers should be 2000-5000 words long (briefing papers should be 1000-2000 words long), with adequate illustrations and references. You can submit your paper online via www.icevirtuallibrary.com/content/journals, where you will also find detailed author guidelines. 